\title{
Virtual reality among the elderly: a usefulness and acceptance study from Taiwan
}

Shabbir Syed-Abdul ${ }^{1,2}$, Shwetambara Malwade ${ }^{1}$, Aldilas Achmad Nursetyo ${ }^{1,2}$, Mishika Sood ${ }^{3}$, Madhu Bhatia ${ }^{4}$,

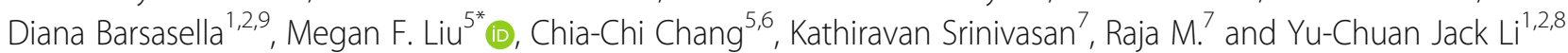

\begin{abstract}
Background: Virtual reality (VR) has several applications in the medical domain and also generates a secure environment to carry out activities. Evaluation of the effectiveness of VR among older populations revealed positive effects of VR as a tool to reduce risks of falls and also improve the social and emotional well-being of older adults. The decline in physical and mental health, the loss of functional capabilities, and a weakening of social ties represent obstacles towards active aging among older adults and indicate a need for support. Existing research focused on the effects of VR among older populations, and its uses and benefits. Our study investigated the acceptance and use of VR by the elderly.

Methods: This pilot study was conducted on 30 older adults who voluntarily participated during March to May 2018. Nine VR applications that promote physical activities, motivate users, and provide entertainment were chosen for this study. Participants were asked to use any one of the applications of their choice for 15 min twice a week for 6 weeks. At the end of 6 weeks, participants were asked to fill out a questionnaire based on the Technology Acceptance Model and a literature review, to evaluate their acceptance of VR technology. Cronbach's alpha reliability analysis was used to test the internal consistency of the questionnaire items. Pearson's product moment correlation was used to examine the validity of the questionnaire. A linear regression and mediation analysis were utilized to identify relationships among the variables of the questionnaire.
\end{abstract}

Results: In total, six male and 24 female participants aged 60 95 years volunteered to participate in the study. Perceived usefulness, perceived ease of use, social norms, and perceived enjoyment were seen to have had significant effects on the intention to use VR. Participants agreed to a large extent regarding the perceived usefulness, perceived enjoyment, and their experience of using VR. Thus, VR was seen to have high acceptance among this elderly population.

Conclusions: Older people have positive perceptions towards accepting and using VR to support active aging. They perceived VR to be useful, easy to use, and an enjoyable experience, implying positive attitudes toward adopting this new technology.

Keywords: Virtual reality, Active aging, Older people, Technology acceptance model

\footnotetext{
* Correspondence: fangliu@tmu.edu.tw

${ }^{5}$ School of Gerontology Health Management, College of Nursing, Taipe

Medical University, 250 Wuxing Street, 11031 Taipei, Taiwan

Full list of author information is available at the end of the article
}

(c) The Author(s). 2019 Open Access This article is distributed under the terms of the Creative Commons Attribution 4.0 International License (http://creativecommons.org/licenses/by/4.0/), which permits unrestricted use, distribution, and reproduction in any medium, provided you give appropriate credit to the original author(s) and the source, provide a link to the Creative Commons license, and indicate if changes were made. The Creative Commons Public Domain Dedication waiver (http://creativecommons.org/publicdomain/zero/1.0/) applies to the data made available in this article, unless otherwise stated. 


\section{Background}

\section{Background of the study}

The World Health Organization (WHO) projects that the global population will become a super-aged society by 2030 [1]. Currently, $12.5 \%$ of people in the world are aged 60 years or older, which is referred to an old society [1], while $24 \%$ of Taiwan's population will be in the older age group by 2030 [2]. Declining mortality rates have been national success stories for the well-being of societies, but they come with consequences of rising morbidity $[3,4]$. A study revealed that declines in physical and mental health, the loss of functional capabilities, and a weakening of social ties represent obstacles to active aging among institutionalized older adults [5]. In addition, life satisfaction among older people, with reduced self-care capacity and physical inactivity (PI), was found to be related to several factors, with social, physical, and mental aspects, such as interacting with each other; especially feeling lonely, the degree of self-care capacity, poor overall health with sleep-wake disturbances, a worried feeling, and poor financial resources [6]. The elderly also tend to have a poor quality of life [7] and develop mobility limitations [8] and functional disabilities [4].

Physical activity is seen to play an important role in improving the functional status, psychological status, and well-being, and has social benefits [9]. Several interventions to improve the physical and cognitive functioning among older people were reported [10-12]. Also, gaming interventions such as virtual environments [13, 14], Pokémon Go $[15,16]$, and Nintendo $\mathrm{Wii}^{\mathrm{TM}}[17]$ are being used as supporting programs for older populations. One such emerging technology is virtual reality (VR), a three-dimensional computer-generated world wherein a person can move about and interact, as if one is actually present in the imaginary space [18]. VR currently has several applications in the medical domain [18], and it also generates a secure environment to carry out certain activities [19, 20]. Evaluations of the effectiveness of VR among older populations revealed positive results for VR as a tool to reduce risks of falls [21$24]$, and high adherence was also observed for home-based VR settings [25] and cognitive rehabilitation [26]. Moreover, it is seen as being well-tolerated by older populations and can stimulate autobiographical memories during reminiscence therapy [27]. VR interventions have shown positive effects on the social and emotional well-being of older adults [28]. Existing research focused on the effects of VR among older populations, and its uses and benefits. However, there is limited research on the acceptance of VR among older adults and how they perceive it.

Despite the benefits offered by VR-based rehabilitation technologies, attitudes among elderly people toward using VR are still unclear [29]. Our study investigated the acceptance and use of VR among an older age group. The Technology Acceptance Model (TAM) was used to assess different factors affecting the acceptance of VR.

\section{Research model}

The TAM was introduced by Davis (1986) and was based on the Theory of Reasoned Action (TRA). The TRA postulates that one's behavior is directly influenced by behavioral intentions which are based on one's attitudes and subjective norms toward a given behavior [30, 31]. The TAM illustrates a user's acceptance of a new technology $[30,32]$. The model has been extensively used in different research fields to anticipate user behaviors. It provides a theoretical basis to help explain relationships among various external variables, perceived usefulness (PU), perceived ease of use (PEOU), attitudes, intention to use (IU), and actual use $[30,33,34]$. Therefore we used the TAM to assess these factors based on a TAM scale developed by Davis [30]. We also included 'social norms' (SNs) [35] and 'perceived enjoyment' (PE) from Venkatesh [36, 37].

Davis proposed that PU is 'the degree to which one presumes that using a specific system would augment his or her job performance'. In our study, PU was defined as 'the degree to which older people presume that use of VR would augment their daily activities'. Also, according to Davis, PEOU refers to 'the degree to which one accepts that using a specific system would be free of effort' [38], and in our study, PEOU was defined as the degree to which older people perceived that using VR was free of effort. According to Davis and other studies, PU and PEOU are important factors in the acceptance of a technology [38, 39]. Thus, in order to verify if the relation between the influence of PEOU and PU in regards to VR acceptance can be applied to this study, we proposed the following hypotheses:

Hypothesis 1 (H1): Perceived usefulness will influence the intention to use VR;

Hypothesis 2 (H2): Perceived ease of use will influence the intention to use VR; and

Hypothesis 3 (H3): Perceived ease of use will influence the perceived usefulness of VR.

SNs are defined as 'a person's perception that most people who are vital to him, think that he should or should not perform the behavior in question' [40] and in our study, SNs were defined as 'older adults' perception that people who are important to them think that they should or should not use VR'. As per previous research, $\mathrm{SNs}$ are seen to influence the intention to use (IU) a technology [41, 42]. Thus, we formulated a hypothesis to verify this in the case of VR:

Hypothesis 4 (H4): Social norms influence the intention to use VR.

According to Van der Heiden, in hedonic systems, "enjoyment" is an important determinant in the intention to use something [43], and Heerink et al. 
indicated that enjoyment is also a factor that influences the intention to use something [44]. "Perceived enjoyment" (PE) has been defined as 'the degree to which using a technology is perceived as fun' [36, 45]. As VR is also partly hedonic, enjoyment could be a factor that should be included in an analysis of acceptance among older adults. Thus, in our study, PE was defined as the degree to which VR was perceived as fun, and the related hypothesis was:

Hypothesis 5 (H5): Perceived enjoyment influences the intention to use VR.

User experience is a concept covering the physical and psychological reactions or behaviors of the user before, during, and after using a technology or a product [46]. Ning and Kim demonstrated that user's experience has an effect on usage intentions through perceived utility [47]. In our study, user experience (UE) was the behavior of older participants after using VR. We formulated two hypotheses as:

Hypothesis 6 (H6): User experience has an effect on perceived usefulness; and

Hypothesis 7 (H7): User experience has an effect on the perceived ease of use.

We composed our research model based on the TAM and a literature review as depicted in Fig. 1. This study attempted to explore the acceptance of the VR among an older population while mitigating problems of aging.

\section{Methodology}

\section{Study setting and participants}

The study was conducted among 30 participants of an older age group (six males and 24 females).

Participants were included under the following criteria: 1) aged 60 years and above, 2) visited the Taipei Medical
University (TMU) aging center, and 3) were willing to participate in the study components.

\section{Data collection}

A signed consent form was received from each participant after explaining to them the objective of the study, which was carried out from March to May 2018. Mandarin Chinese versions of the questionnaire and consent form were filled out by participants. The questionnaire is given in Additional file 1 (based on the TAM and SNs, UE, and PE from Venkatesh). The questionnaire was used to collect participants' perceptions about their acceptance of VR. Six sets of questions were clustered under the variables of $\mathrm{PU}$, PEOU, PE, SN, UE, and IU based on a literature review.

We used the Vive htc VR system for the study. These devices contained nine different applications (Appendix) that encouraged physical activity, motivated, and provided entertainment to older people. We ensured that participants accessed the different VR applications at least once during the study period. Participants were asked to use VR for 15 min twice a week for 6 weeks and respond to the questionnaire in Additional file 1 at the end of the study. A 5-point Likert scale was used to score the questions, in which participants were asked to agree or disagree based on a ranking from 5 to 1 , where 5 indicated strong agreement, 3 indicated a neutral opinion, and 1 indicated strong disagreement. Information obtained from respondents was centered on their experience and perceptions while using VR. The study was approved by the ethics committee of the Taipei Medical University-Joint Institutional Review Board.

\section{Data analysis}

Researchers analyzed the data using SPSS vers. 20 (SPSS, Chicago, IL, USA). Pearson's product moment correlation was conducted to examine the criterion validity of the questionnaire. Cronbach's alpha reliability analysis was

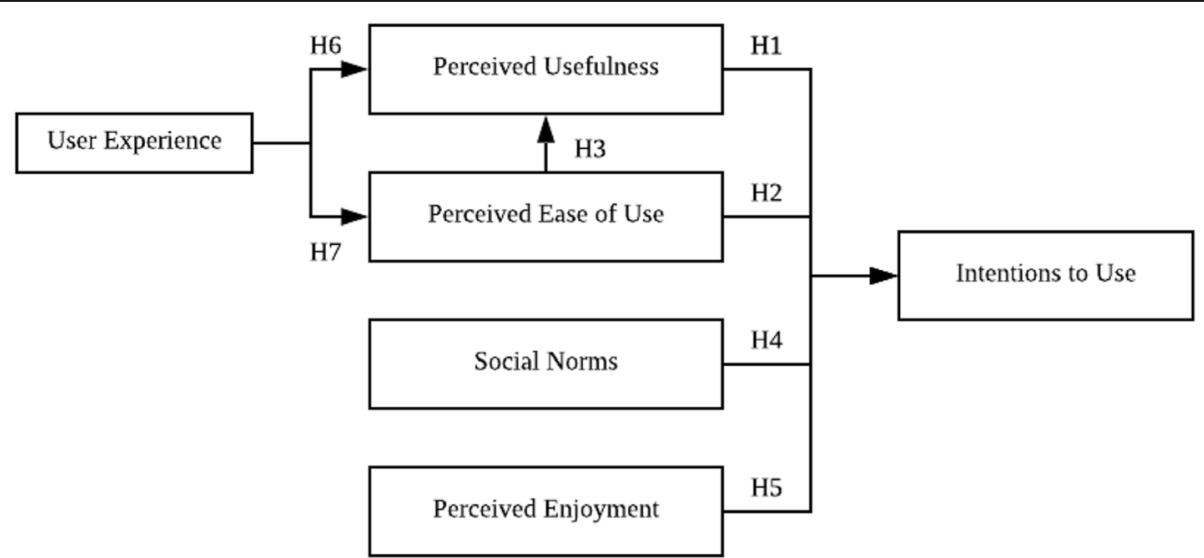

Fig. 1 Research model for the study. This figure describes the research model developed for the study based on TAM and reviewed literature. $\mathrm{H} 1-\mathrm{H} 7$ are hypotheses $1 \sim 7$, which describe the influence of one variable on the other 
Table 1 Characteristics of participants

\begin{tabular}{llll}
\hline Age (years) & Male 6 (20\%) & Female 24 (80\%) & Total $(\%) n=30$ \\
\hline $60 \sim 65$ & 1 & 7 & $8(26.7 \%)$ \\
$65 \sim 70$ & 3 & 4 & $7(23.3 \%)$ \\
$70 \sim 75$ & 1 & 7 & $8(26.7 \%)$ \\
$75 \sim 80$ & 1 & 3 & $4(13.3 \%)$ \\
$80 \sim 85$ & 0 & 2 & $2(6.7 \%)$ \\
$85 \sim 90$ & 0 & 0 & 0 \\
$>90$ & 0 & 1 & $1(3.3 \%)$ \\
\hline
\end{tabular}

used to test the internal consistency of the questionnaire items. A linear regression analysis was utilized to identify relationships among the variables: PU, PEOU, UE, SNs, $\mathrm{PE}$, and IU. A mediation analysis was conducted to determine the mediating effect of different variables in the questionnaire.

\section{Results}

\section{Characteristics of participants}

Table 1 shows characteristics of the 30 older participants. Of these, six (20\%) were males, and 24 (80\%) were females, with the highest percentage of participants aged 70 75 years.

Figure 2 shows a summary of the responses of the 30 older participants. They were asked about the PU of VR, and $77.8 \%$ agreed that VR helped raise their mood, and entertain and keep them motivated to do their daily activities. Participants who believed that VR was easy to use accounted for 64.4 , and $80 \%$ of participants found it enjoyable. For subjective norms with regards to the support of the use of VR by family, friends, and caretakers, $55.6 \%$ agreed, and $77.8 \%$ of users expressed a positive experience. Around $71.7 \%$ of participants intended to use VR in the future.

\section{Summary statistics of variables}

Summary statistics and frequency distributions of all the variables are shown in Table 2 , with a mean range of $3.27 \sim 4.07$, and standard deviation of $\leq 0.661$.

\section{Validity testing of the questionnaire}

The validity coefficient and $p$ values of items in the questionnaire are shown in Table 3.

The critical value of Pearson's product-moment was 0.361 , according to the table of critical values [48], for 30 respondents. As shown in Table 3, for all our variables, the $r$ table product moment (rxy) was $>0.361$ for $p$ values of $<0.05$.

\section{Cronbach's a reliability analysis}

Cronbach's $\alpha$ reliability analysis was conducted to assess the internal consistency and reliability of the variables in the study (Table 4).

\section{Hypothesis testing using a linear regression analysis}

Seven hypotheses were formulated based on the initial TAM model and a literature review. Each hypothesis was tested for significance based on the regression statistics. Table 5 presents the summary of the regression data for each hypothesis. Larger beta values were observed for larger $t$ values and smaller $p$ values across all hypotheses.

All the hypotheses are detailed as below:

$\mathrm{H} 1$ : For $\mathrm{H} 1$, the regression analysis gave a $p$ value of 0.000 , which indicated that PU had a significant influence on IU. $R^{2}$ for the regression equation was 0.474, indicating that the predictor factor PU explained 47.4\% of IU. The un-standardized $\beta$ coefficient indicated that for every unit of increase in PU, a 0.625 increase in the units of IU was predicted.

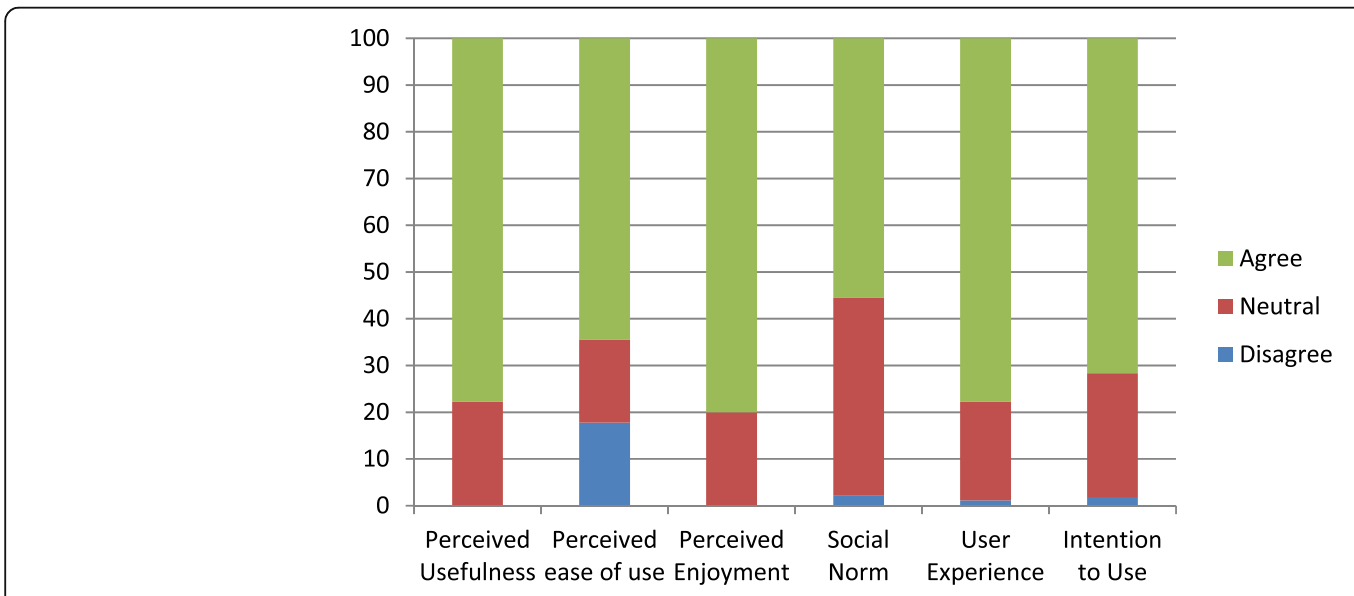

Fig. 2 Summary of responses of participants. This figure explains the graph of the responses of the participants in terms of percentage 
Table 2 Summary statistics and frequency distributions of variables in the questionnaire

\begin{tabular}{lll}
\hline Variable description & Mean & Std. deviation (SD) \\
\hline Perceived usefulness (PU) & & \\
PU1 & 3.87 & 0.571 \\
PU2 & 3.80 & 0.610 \\
PU3 & 4.07 & 0.583 \\
Perceived ease of use (PEOU) & & \\
PEOU1 & 3.87 & 0.571 \\
PEOU2 & 3.27 & 0.556 \\
PEOU3 & 3.67 & 0.583 \\
Social norms (SNs) & & \\
SN1 & 3.43 & 0.626 \\
SN2 & 3.77 & 0.626 \\
SN3 & 3.67 & 0.661 \\
User experience (UE) & & \\
UE1 & 4.07 & 0.583 \\
UE2 & 3.77 & 0.626 \\
UE3 & 3.83 & 0.592 \\
Intention to use (IU) & & 0.615 \\
IU1 & 3.63 & \\
IU2 & 3.90 & \\
\hline
\end{tabular}

$\mathrm{H} 2$ : For $\mathrm{H} 2$, the regression analysis gave a $p$ value of 0.000 , which indicated that PEOU had a significant influence on IU. $R^{2}$ for the regression equation was 0.555 , indicating that the predictor factor PEOU explained $55.5 \%$ of IU. The un-standardized $\beta$ coefficient indicated that for every unit of increase in PU, a 3.113 increase in the units of IU was predicted.

$\mathrm{H} 3$ : For $\mathrm{H} 3$, the regression analysis gave a $p$ value of 0.002 , which indicated that PEOU had a significant influence on PU. $R^{2}$ for the regression equation was 0.301, indicating that the predictor factor PEOU explained $30.1 \%$ of PU. The un-standardized $\beta$ coefficient indicated that for every unit of increase in PEOU, a 2.523 increase in the units of PU was predicted.

$\mathrm{H} 4$ : For $\mathrm{H} 4$, the regression analysis gave a $p$ value of 0.000 , which indicated that SNs had a significant influence on IU. $R^{2}$ for the regression equation was 0.516, indicating that the predictor factor PEOU explained $51.61 \%$ of IU. The un-standardized $\beta$ coefficient indicated that for every unit of increase in PEOU, a 0.717 increase in the units of IU was predicted.

$\mathrm{H} 5$ : For $\mathrm{H} 5$, the regression analysis gave a $p$ value of 0.000 , which indicated that PE had a significant influence on IU. $R^{2}$ for the regression equation was
Table 3 Criterion validity test of the questionnaire with Pearson's product-moment correlations

\begin{tabular}{|c|c|c|}
\hline Item in the questionnaire & rxy & $p$ value \\
\hline VR is useful to me for entertainment. (PU1) & 0.727 & 0.000 \\
\hline $\begin{array}{l}\text { VR improves engagement and motivates daily } \\
\text { activities. (PU2) }\end{array}$ & 0.706 & 0.000 \\
\hline VR is an efficient tool to raise my mood. (PU3) & 0.590 & 0.001 \\
\hline It is easy for me to become skillful at using VR. (PEOU1) & 0.752 & 0.000 \\
\hline Learning to operate VR was easy for me. (PEOU2) & 0.678 & 0.000 \\
\hline Overall I find it easy to use VR. (PEOU3) & 0.797 & 0.000 \\
\hline I find VR very attractive to use. (PE1) & 0.842 & 0.000 \\
\hline I enjoy using VR. (PE2) & 0.791 & 0.000 \\
\hline I have fun when I use VR. (PE3) & 0.813 & 0.000 \\
\hline My family members think I should use VR. (SN1) & 0.787 & 0.000 \\
\hline $\begin{array}{l}\text { People who are friends and acquaintances have } \\
\text { influence on my intention to use VR. (SN2) }\end{array}$ & 0.842 & 0.000 \\
\hline $\begin{array}{l}\text { People who take care of me encourage me to } \\
\text { use VR. (SN3) }\end{array}$ & 0.629 & 0.000 \\
\hline VR will give me new experiences. (UE1) & 0.526 & 0.003 \\
\hline VR was comfortable to use. (UE2) & 0.829 & 0.000 \\
\hline $\begin{array}{l}\text { Overall, I had a positive experience when using VR. } \\
\text { (UE3) }\end{array}$ & 0.829 & 0.000 \\
\hline $\begin{array}{l}\text { In the future, I intend to use the device for mental } \\
\text { relaxation. (IU1) }\end{array}$ & 0.813 & 0.000 \\
\hline $\begin{array}{l}\text { In the future, VR will help keep my mind sharp and } \\
\text { alert. (IU2) }\end{array}$ & 0.838 & 0.000 \\
\hline
\end{tabular}

$\mathrm{VR}$, virtual reality

0.708, indicating that the predictor factor PE explained $70.8 \%$ of IU. The un-standardized $\beta$ coefficient indicated that for every unit of increase in PE, a 0.784 increase in the units of IU was predicted.

$\mathrm{H6}$ : For $\mathrm{H} 5$, the regression analysis gave a $p$ value of 0.000 , which indicated that UE had a significant influence on PU. $R^{2}$ for the regression equation was 0.442 , indicating that the predictor factor UE explained $44.2 \%$ of IU. The un-standardized $\beta$ coefficient indicated that for every unit of increase in UE, a 2.065 increase in the units of PU was predicted. $\mathrm{H} 7$ : For $\mathrm{H7}$, the regression analysis gave a $p$ value of 0.001 , which indicated that UE had a significant influence on PEOU. $R^{2}$ for the regression equation was 0.351 , indicating that the predictor factor UE explained

Table 4 Cronbach's a values

\begin{tabular}{ll}
\hline Item & Cronbach's a \\
\hline Perceived usefulness & 0.922 \\
Perceived ease of use & 0.925 \\
Perceived enjoyment & 0.903 \\
Social norms & 0.910 \\
User experience & 0.913 \\
Intention to use & 0.899 \\
\hline
\end{tabular}


Table 5 Regression statistics for the formulated hypotheses

\begin{tabular}{|c|c|c|c|c|c|c|c|c|c|}
\hline \multirow[t]{2}{*}{ Hypothesis } & \multirow{2}{*}{$\begin{array}{l}\text { Independent } \\
\text { variable }\end{array}$} & \multirow{2}{*}{$\begin{array}{l}\text { Dependent } \\
\text { variable }\end{array}$} & \multicolumn{2}{|c|}{ Un-standardized coefficients } & \multirow[t]{2}{*}{$F$} & \multirow[t]{2}{*}{$t$} & \multirow[t]{2}{*}{$p$} & \multirow[t]{2}{*}{$R^{2}$} & \multirow{2}{*}{$\begin{array}{l}\text { Hypothesi } \\
\text { supported }\end{array}$} \\
\hline & & & $\beta$ & Standard Error & & & & & \\
\hline $\mathrm{H} 1$ & PU & IU & 0.625 & 0.125 & 25.205 & 5.020 & 0.000 & 0.474 & Yes \\
\hline $\mathrm{H} 2$ & PEOU & IU & 3.113 & 0.527 & 34.920 & 5.909 & 0.000 & 0.555 & Yes \\
\hline $\mathrm{H} 3$ & PEOU & PU & 2.523 & 0.727 & 12.058 & 3.472 & 0.002 & 0.301 & Yes \\
\hline $\mathrm{H} 4$ & SNs & IU & 0.717 & 0.131 & 29.845 & 5.463 & 0.000 & 0.516 & Yes \\
\hline H5 & PE & IU & 0.784 & 0.095 & 67.870 & 8.238 & 0.000 & 0.708 & Yes \\
\hline H6 & UE & PU & 2.065 & 0.439 & 22.137 & 4.705 & 0.000 & 0.442 & Yes \\
\hline $\mathrm{H} 7$ & UE & PEOU & 0.401 & 0.103 & 15.170 & 3.895 & 0.001 & 0.351 & Yes \\
\hline
\end{tabular}

PU, perceived usefulness; IU, intention to use; PEOU, perceived ease of use; SNs, social norms; PE, perceived enjoyment; UE, user experience

35.1\% of PEOU. The un-standardized $\beta$ coefficient indicated that for every unit of increase in UE, a 0.401increase in the unit of PEOU was predicted.

\section{Mediation analysis}

Table 6 describes mediating factors of possible pathways, using a bootstrap analysis method.

Figure 3 describes models of the mediation effect of different variables through pathways $A, B$, and $C^{\prime}$. In models $3 \mathrm{C}$ and $3 \mathrm{E}$, paths $\mathrm{A}$ and $\mathrm{B}$ were significant, and $\mathrm{C}$ was not significant. Table 5 indicates that $\mathrm{H} 1$ was significant, which was not supported when mediation was used. Thus, SNs provided a strong mediating effect for determining the influence of PU on IU, and PE provided a strong mediating effect for determining the influence of PU on IU. Models 3F and 3G indicated that paths A, $\mathrm{B}$, and $\mathrm{C}$ were significant; however, the mediators did not give significant effects for the models.

\section{Discussion}

In this study, based on the TAM and a literature review, a research model was developed to determine factors influencing the intention to use VR among an older population.

Validity and reliability tests were conducted to ensure that the results were reliable and consistent. A criterion validity test was conducted with Pearson's product- moment correlation. The $\mathrm{r}$ table product moment was $<0.361$ for all of our variables; this value is from a table of critical values of the Pearson product-moment [48]. Furthermore, $p$ values were all $<0.05$, which implies that all of the variables were valid. According to Tavakol and Dennik [49], a Cronbach's alpha value of $>0.7$ is considered an acceptable value in terms of the reliability level. Cronbach's $\alpha$ values for all variables in our study were $>0.70$, which confirmed the internal reliability (Table 2). Linear regression statistics suggested that all of the formulated hypotheses were supported. SNs and perceived experience showed significant mediating effects in determining the influence of PU on the IU VR.

We conducted the study on the usefulness and acceptance of VR among an aged population. Participants agreed to a large extent to the PU, PE, and their experience of using VR. The PU and PEOU were seen to predict the IU VR. This suggests that older people consider using technology which is easy to use and also based on its usefulness. Our results are consistent with Davis' postulation that users tend to adopt a technology based on the tasks it can perform for them and also on the level of difficulty associated with its usage [36, 38]. Similarly, SNs are seen to have a direct effect on the IU VR, which was also seen in the case of other technologies previously tested $[41,42,50]$. PE is seen as a more-significant predictor of IU compared to PU in our study, suggesting that older people regard the level of enjoyment as an

Table 6 Bootstrap analysis of the mediation effect

\begin{tabular}{|c|c|c|c|c|c|c|c|c|c|}
\hline No & Path A & Path B & Path $C^{\prime}$ & Mediating factor & $\begin{array}{l}\text { Mediation effect } \\
\text { (full/partial) }\end{array}$ & $\begin{array}{l}\text { Indirect effect } \\
\text { (value) }\end{array}$ & $p$ value & $\begin{array}{l}95 \% \mathrm{Cl} \\
\text { lower }\end{array}$ & $\begin{array}{l}95 \% \mathrm{Cl} \\
\text { upper }\end{array}$ \\
\hline 1 & $\mathrm{UE} \rightarrow \mathrm{PEOU}$ & $\mathrm{PEOU} \rightarrow \mathrm{PU}$ & $\mathrm{UE} \rightarrow \mathrm{PU}$ & PEOU & Partial & 0.1305 & 0.2054 & -0.0066 & 0.3072 \\
\hline 2 & $\mathrm{PEOU} \rightarrow \mathrm{PU}$ & $\mathrm{PU} \rightarrow \mathrm{SNS}$ & $\mathrm{PEOU} \rightarrow \mathrm{SNs}$ & PU & Partial & 0.1051 & 0.1161 & -0.0442 & 0.3480 \\
\hline 3 & $\mathrm{PU} \rightarrow \mathrm{SNS}$ & $\mathrm{SNs} \rightarrow \mathrm{IU}$ & $\mathrm{PU} \rightarrow \mathrm{IU}$ & SN & Full & 0.3124 & 0.0142 & 0.0713 & 0.8124 \\
\hline 4 & $\mathrm{PEOU} \rightarrow \mathrm{SNS}$ & $\mathrm{SNs} \rightarrow \mathrm{IU}$ & $\mathrm{PEOU} \rightarrow \mathrm{IU}$ & SN & Partial & 0.1962 & 0.0534 & -0.0373 & 0.4613 \\
\hline 5 & $\mathrm{PU} \rightarrow \mathrm{PE}$ & $\mathrm{PE} \rightarrow \mathrm{IU}$ & $\mathrm{PU} \rightarrow \mathrm{IU}$ & $\mathrm{PE}$ & Full & 0.5064 & 0.0005 & 0.2799 & 0.8206 \\
\hline 6 & $\mathrm{PEOU} \rightarrow \mathrm{PE}$ & $\mathrm{PE} \rightarrow \mathrm{IU}$ & $\mathrm{PEOU} \rightarrow \mathrm{IU}$ & PE & Partial & 0.6427 & 0.0005 & 0.3372 & 1.3620 \\
\hline 7 & $\mathrm{PEOU} \rightarrow \mathrm{PU}$ & $\mathrm{PU} \rightarrow \mathrm{IU}$ & $\mathrm{PEOU} \rightarrow \mathrm{IU}$ & PU & Partial & 0.1575 & 0.0263 & 0.0558 & 0.3539 \\
\hline
\end{tabular}

$\mathrm{Cl}$, confidence interval; UE, user experience; PEOU, perceived ease of use; PU, perceived usefulness; SNs, social norms; IU, intention to use 


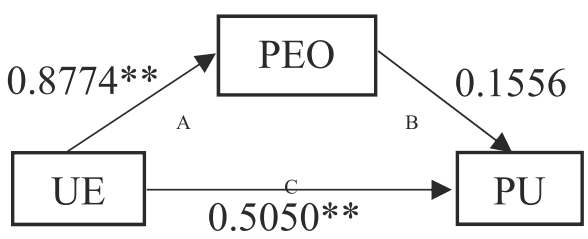

A. Indirect effect of user experience (UE) on perceived usefulness (PU) through perceived ease of use (PEOU).

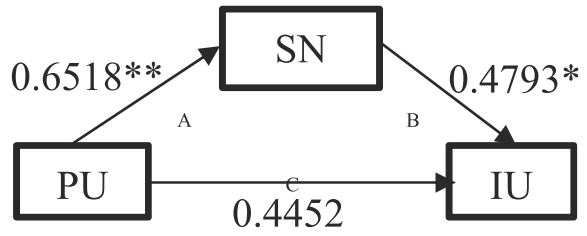

C. Indirect effect of perceived usefulness (PU) on intention to use (IU) through social norms (SNs).

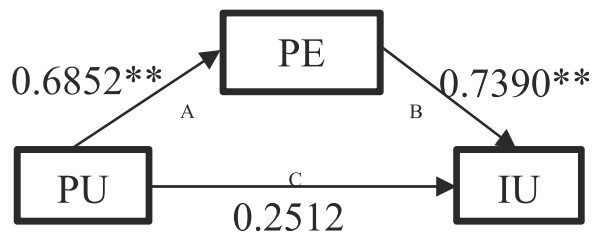

E. Indirect effect of perceived usefulness (PU) on intention to use (IU) through perceived enjoyment $(\mathrm{PE})$.

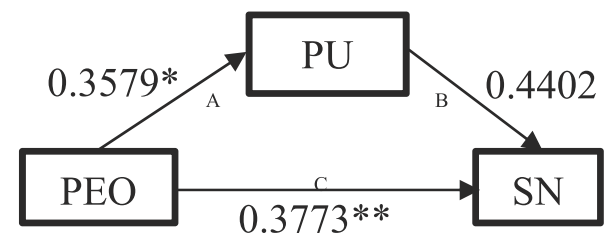

G. Indirect effect of perceived ease of use (PEOU) on social norms (SNs) through perceived usefulness (PU).

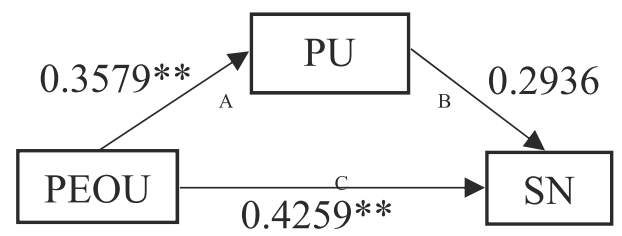

B. Indirect effect of perceived ease of use (PEOU) on social norms (SNs) through perceived usefulness (PU).

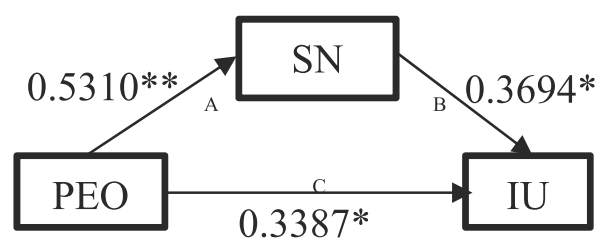

D. Indirect effect of perceived usefulness (PU) on intention to use (IU) through perceived enjoyment (PE).

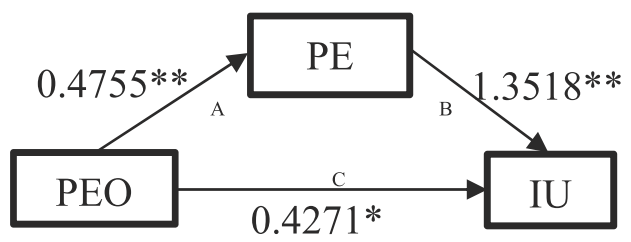

F. Indirect effect of perceived ease of use (PEOU) on intention to use (IU) through perceived enjoyment $(\mathrm{PE})$.

$* p<0.05, * * p<0.01, * * * p<0.0001$.

Fig. 3 Models of mediating effects for different variables through pathways $\mathbf{a}$, $\mathbf{b}$, and $\mathbf{c}^{\prime}$. This figure describes the different models for mediating effects among different variables 
important factor [51]. This was also determined by Van der Heiden [43]. User experience was seen to have a significant effect on the PU and PEOU. This implies that elderly users regard the experience as an important determinant of the usefulness of and ease of using VR.

PU, PEOU, and PE are among important factors to be considered when developing VR applications for use among elderly populations. Older people seemed to enjoy VR; however, poor health may prevent such new experiences, which necessitates one consider their preferences and remove barriers that can limit the use and enjoyment of VR [52].

VR technology can be introduced as one of the devices that can motivate older people to be more physically active $[19,20]$. Older people found it useful in motivating them in their daily activities. In addition to contemporary comfort and ease of using VR, older people also intended to use it for mental relaxation in the future. VR was comfortable and provided a new and positive experience for them, which was also consistent with a previous study [53].

VR equipment is expensive if the device includes more features like haptic feedback, thus limiting its adoption [54]. One more limitation of VR equipment and programs is that if used for an extended period, it may cause a dizzy feeling in older adults and in turn decrease personal interactions and conversation among older people and their families [53]. Bearing in mind these factors, we would like to encourage older adults to willingly participate in using VR applications by understanding its uses as well as considering its limitations [55]. Our study provides an understanding of perceptions and preferences of the elderly towards the use of VR. In addition, it also indicates positive perceptions of the elderly towards the usefulness of VR to support aging.

Despite providing meaningful insights into the adoption and acceptance of VR among older people, our study also had some limitations. First, the small number of participants in the study limited the broader perspectives that could be accessed from larger numbers of respondents. In the future, adding more participants to the study and conducting the study for a longer duration would help ensure feedback from a larger population. Also, we would also select a broader range of VR programs including a variety of topics in order to respond to older adults' interests and preferences. Second, our study included VR apps which encouraged individual participation. Future consideration of VR apps that could allow participation in groups and competition within specific programs could help promote social interactions in future versions of the study.

\section{Conclusions}

Our study demonstrates the use and acceptance towards the adoption of VR among older population. Perceptions that VR was useful, was easy to use, and provided an enjoyable experience showed the positive attitudes of older adults toward adopting this new technology. Future developments could be made considering these perceptions among elderly populations.

\section{Appendix}

Virtual Reality applications used during the study

1. The Lab

2. Everest VR

3. The Body VR: Journey Inside a Cell

4. To The Top

5. Waltz of the Wizard

6. Google Earth VR

7. Found

8. Sparc

9. Final Soccer VR

\section{Additional file}

Additional file 1: Acceptance of the Virtual Reality (VR) Experience among the Elderly: Questionnaire. (DOCX 16 kb)

\section{Abbreviations}

H1 7: Hypotheses 1 7; IU: Intention to use; PE: Perceived enjoyment; PEOU: Perceived ease of use; PI: Physical inactivity; PU: Perceived usefulness; SNs: Social norms; TAM: Technology Acceptance Model; TMU: Taipei Medical University; TRA: Theory of Reasoned Action; VR: Virtual reality; WHO: World Health Organization

\section{Acknowledgments}

We are thankful to the Ministry of Science and Technology (MOST) and Taipei Medical University for providing the necessary funding to carry out this research work. We are thankful to the Research Center for Active Ageing, Taipei Medical University for facilitating the data collection of participants.

\section{Authors' contributions}

Conceptualization: SSA, MFL, and SM; data analysis: SM, AAN, MS, MB, and DB; methodology: SSA and MFL; supervision: SSA, MFL, SM, and CCC; validation: SSA, MFL, SM, CCC, KS, RM and YCL; writing of the original draft: SSA, SM, AAN, MS, and MB; writing - review and editing: SSA, SM, MFL, KS, $\mathrm{RM}$ and $\mathrm{YCL}$. All authors read and approved the final version of the manuscript.

\section{Funding}

This work was supported by Ministry of Science and Technology, Taiwan [106-2923-E-038-001-MY2, 107-2923-E-038-001-MY2, and 106-2221-E-038005]; Taipei Medical University [106-3805-004-111]; and Wanfang Hospital [106TMU-WFH-01-4]

\section{Availability of data and materials}

The data analyzed during the current study are available from the corresponding author on reasonable request.

\section{Ethics approval and consent to participate}

This study was approved by the ethical committee of Taipei Medical University-Joint Institutional Review Board, under reference no. N201712017. A written informed consent was obtained from all the participants of the study.

Consent for publication

Not applicable. 


\section{Competing interests}

The authors declare that they have no competing interests.

\begin{abstract}
Author details
'International Center for Health Information Technology (ICHIT), Taipei Medical University, Taipei, Taiwan. ${ }^{2}$ Graduate Institute of Biomedical Informatics, Taipei Medical University, Taipei, Taiwan. ${ }^{3}$ Chitkara University, Punjab, India. ${ }^{4}$ I.K. Gujral Punjab Technical University, Kapurthala, Punjab, India. ${ }^{5}$ School of Gerontology Health Management, College of Nursing, Taipei Medical University, 250 Wuxing Street, 11031 Taipei, Taiwan. ${ }^{6} \mathrm{College}$ of Interdisciplinary Studies, Taipei Medical University, Taipei, Taiwan. ${ }^{7}$ Schoo of Information Technology and Engineering, Vellore Institute of Technology (VIT), Vellore, India. ${ }^{8} \mathrm{TMU}$ Research Center of Cancer Translational Medicine, Taipei Medical University, Taipei, Taiwan. ${ }^{9}$ Tasikmalaya Polytechnic of Ministry of Health, Tasikmalaya, West Java, Indonesia.
\end{abstract}

\section{Received: 13 January 2019 Accepted: 18 July 2019 Published online: 19 August 2019}

\section{References}

1. United Nations DoEaSA, Population Division. World Ageing Population2015.

2. Council ND. Populations Projection for Republic of China : 2016-2060 2016 [Available from: https://www.ndc.gov.tw/en/cp.aspx?n=2E5DCB04C64512CC.

3. Harper S. Economic and social implications of aging societies. Science. 2014 346(6209):587-91.

4. Bloom DE, Chatterii S, Kowal P, Lloyd-Sherlock P, McKee M, Rechel B, et al. Macroeconomic implications of population ageing and selected policy responses. Lancet. 2015;385(9968):649-57.

5. Fernandez-Mayoralas G, Rojo-Perez F, Martinez-Martin P, Prieto-Flores ME, Rodriguez-Blazquez C, Martin-Garcia S, et al. Active ageing and quality of life: factors associated with participation in leisure activities among institutionalized older adults, with and without dementia. Aging Ment Health. 2015:19(11):1031-41.

6. Borg C, Hallberg IR, Blomqvist K. Life satisfaction among older people (65+) with reduced self-care capacity: the relationship to social, health and financial aspects. J Clin Nurs. 2006;15(5):607-18.

7. Blair CK, Robien K, Inoue-Choi M, Rahn W, Lazovich D. Physical inactivity and risk of poor quality of life among elderly cancer survivors compared to women without cancer: the lowa Women's health study. J Cancer Surviv. 2016;10(1):103-12

8. Vaz Fragoso CA, Miller ME, King AC, Kritchevsky SB, Liu CK, Myers VH, et al. Effect of structured physical activity on sleep-wake behaviors in sedentary elderly adults with mobility limitations. J Am Geriatr Soc. 2015;63(7):1381-90.

9. Services USHaH. Physical Activity Guidelines Advisory Committee Report Washington, DC : U.S. Department of Health and Human Services . 2008 [cited 20198 April 2019]. Available from: https://health.gov/paguidelines/2008/.

10. Bherer L. Cognitive plasticity in older adults: effects of cognitive training and physical exercise. Ann N Y Acad Sci. 2015;1337(1):1-6.

11. Bauman A, Merom D, Bull FC, Buchner DM, Fiatarone Singh MA. Updating the evidence for physical activity: summative reviews of the epidemiological evidence, prevalence, and interventions to promote "active aging". The Gerontologist. 2016:56(Suppl_2):S268-S80.

12. Morris JH, MacGillivray S, Mcfarlane S. Interventions to promote long-term participation in physical activity after stroke: a systematic review of the literature. Arch Phys Med Rehabil. 2014;95(5):956-67.

13. Theng Y-L, Lee JW, Patinadan PV, Foo SS. The use of videogames, gamification, and virtual environments in the self-management of diabetes: a systematic review of evidence. Games for health journal. 2015;4(5):352-61.

14. Donath $L$, Rössler $R$, Faude $O$. Effects of virtual reality training (exergaming) compared to alternative exercise training and passive control on standing balance and functional mobility in healthy community-dwelling seniors: a meta-analytical review. Sports Med. 2016;46(9):1293-309.

15. Howe KB, Suharlim C, Ueda P, Howe D, Kawachi I, Rimm EB. Gotta catch'em all! Pokémon GO and physical activity among young adults: difference in differences study bmj. 2016:355:i6270.

16. Althoff T, White RW, Horvitz E. Influence of Pokémon Go on physical activity: study and implications. Journal of medical Internet research. 2016;18(12).

17. Chao Y-Y, Scherer YK, Montgomery CA. Effects of using Nintendo Wii ${ }^{\text {TM }}$ exergames in older adults: a review of the literature. Journal of aging and health. 2015;27(3):379-402.
18. Moline J. Virtual reality for health care: a survey. Studies in health technology and informatics. 1997:44:3-34.

19. de Bruin ED, Schoene D, Pichierri G, Smith ST. Use of virtual reality technique for the training of motor control in the elderly. Some theoretical considerations. Z Gerontol Geriatr. 2010;43(4):229-34.

20. Molina Kl, Ricci NA, de Moraes SA, Perracini MR. Virtual reality using games for improving physical functioning in older adults: a systematic review. Journal of neuroengineering and rehabilitation. 2014;11(1):156.

21. Hwang J, Lee $\mathrm{S}$. The effect of virtual reality program on the cognitive function and balance of the people with mild cognitive impairment. The Journal of Physical Therapy Science. 2017;29:1283-6.

22. Saldana SJ, Marsh AP, Rejeski WJ, Haberl JK, Wu P, Rosenthal S, et al. Assessing balance through the use of a low-cost head-mounted display in older adults: a pilot study. Clin Interv Aging. 2017;12:1363-70.

23. Suárez H, Suárez A, Lavinsky L. Postural adaptation in elderly patients with instability and risk of falling after balance training using a virtual-reality system. International Tinnitus Journal. 2006;12(1):41-4.

24. Cho GH, Hwangbo G, Shin HS. The effects of virtual reality-based balance training on balance of the elderly. J Phys Ther Sci. 2014;26(4):615-7.

25. Broeren J, Claesson L, Goude D, Rydmark M, Sunnerhagen KS. Virtual rehabilitation in an activity Centre for community-dwelling persons with stroke. The possibilities of 3-dimensional computer games. Cerebrovasc Dis. 2008:26(3):289-96.

26. García-Betances Rl, Jiménez-Mixco V, Arredondo MT, Cabrera-Umpiérrez MF. Using Virtual Reality for Cognitive Training of the Elderly. American Journal of Alzheimer's Disease \& Other Dementias. 2014;30(1):49-54.

27. Benoit M, Guerchouche R, Petit P-D, Chapoulie E, Manera V, Chaurasia G, et al. Is it possible to use highly realistic virtual reality in the elderly? A feasibility study with image-based rendering. Neuropsychiatr Dis Treat. 2015; 11:557-63.

28. Lin CX, Lee C, Lally D, Coughlin JF, editors. Impact of Virtual Reality (VR) Experience on Older Adults' Well-Being2018; Cham: Springer International Publishing.

29. Miller KJ, Adair BS, Pearce AJ, Said CM, Ozanne E, Morris MM. Effectiveness and feasibility of virtual reality and gaming system use at home by older adults for enabling physical activity to improve health-related domains: a systematic review. Age Ageing. 2014;43(2):188-95.

30. Davis FD, Bagozzi RP, Warshaw PR. User Acceptance of Computer Technology: A Comparison of Two Theoretical Models. 1989;35(8):982-1003.

31. Masrom M. Technology acceptance model and E-learning2007.

32. Wang Y, Anne A, Ropp T. Applying the technology acceptance model to understand aviation students' perceptions toward augmented reality maintenance training instruction. International Journal of Aviation, Aeronautics, and Aerospace. 2016;3(4):3.

33. Park SY. An analysis of the technology acceptance model in understanding university students' behavioral intention to use e-learning. Educational technology \& society. 2009;12(3):150-62.

34. Legris $P$, Ingham J, Collerette P. Why do people use information technology? A critical review of the technology acceptance model. Inf Manag. 2003;40(3):191-204

35. Venkatesh V, Morris MG, Davis GB, Davis FD. User acceptance of information technology: toward a unified view. MIS Q. 2003;27(3):425-78.

36. Venkatesh $\mathrm{V}$. Determinants of perceived ease of use: integrating control, intrinsic motivation, and emotion into the technology acceptance model. Inf Syst Res. 2000;11(4):342-65.

37. Hsiao $\mathrm{CH}$, Yang $\mathrm{C}$. The intellectual development of the technology acceptance model: a co-citation analysis. Int J Inf Manag. 2011;31(2):128-36.

38. Davis FD. Perceived usefulness, perceived ease of use, and user acceptance of information technology. MIS Q. 1989;13(3):319-40.

39. Wallace LG, Sheetz SD. The adoption of software measures: a technology acceptance model (TAM) perspective. Inf Manag. 2014;51(2):249-59.

40. Park HS. Relationships among attitudes and subjective norms: testing the theory of reasoned action across cultures. Commun Stud. 2000;51(2):162-75.

41. Dean RN, Farrell JM, Kelley ML, Taylor MJ, Rhodes RE. Testing the efficacy of the theory of planned behavior to explain strength training in older adults. J Aging Phys Act. 2007;15(1):1-12.

42. Keung Yau H, Chung Ho T. The Influence of Subjective Norm on Behavioral Intention In Using E-Learning: An Empirical Study in Hong Kong Higher Education2015. 912-4 p.

43. Van der Heiden $\mathrm{H}$. User acceptance of hedonic information systems. MIS Q. 2004;28(4):695-704. 
44. Heerink M, Kröse B, Wielinga B, Evers V, editors. Enjoyment, intention to use and actual use of a conversational robot by elderly people. 2008 3rd ACM/ IEEE International Conference on Human-Robot Interaction (HRI); 2008 1215 March 2008.

45. Lee J, Kim J, Choi JY. The adoption of virtual reality devices: the technology acceptance model integrating enjoyment, social interaction, and strength of the social ties. Telematics Inform. 2019;39:37-48.

46. Jeong SC, Byun JS, Jeong YJ. The effect of user experience and perceived similarity of smartphone on acceptance intention for smartwatch. ICIC Express Letters. 2016;10(7):1613-9.

47. Ning X, Kim K-S. An empirical study of user experience (UX) factors affecting continued usage intention of smartphone. 2012;9(4):91-118

48. Bewick V, Cheek L, Ball J. Statistics review 7: correlation and regression. Crit Care. 2003; $7(6): 451$.

49. Tavakol M, Dennick R. Making sense of Cronbach's alpha. Int J Med Educ. 2011;2:53-5

50. Baker S, Waycott J, Pedell S, Hoang T, Ozanne E, editors. Older People and Social Participation: From Touch-Screens to Virtual Realities. Proceedings of the International Symposium on Interactive Technology and Ageing Populations; 2016: ACM.

51. Chesney T. An acceptance model for useful and fun information systems. Human Technology: An Interdisciplinary Journal on Humans in ICT Environments. 2006.

52. Roberts AR, De Schutter B, Franks K, Radina ME. Older adults' experiences with audiovisual virtual reality: perceived usefulness and other factors influencing technology acceptance. Clin Gerontol. 2019;42(1):27-33.

53. Jeng M-Y, Pai F-Y, Yeh T-M. The virtual reality leisure activities experience on elderly people. Appl Res Qual Life. 2017;12(1):49-65.

54. Coburn JQ. An analysis of enabling techniques for highly-accessible low-cost virtual reality hardware in the collaborative engineering design process. 2017.

55. Regan EC, Price KR. The frequency of occurrence and severity of side-effects of immersion virtual reality. Aviat Space Environ Med. 1994;65(6):527-30.

\section{Publisher's Note}

Springer Nature remains neutral with regard to jurisdictional claims in published maps and institutional affiliations.

Ready to submit your research? Choose BMC and benefit from:

- fast, convenient online submission

- thorough peer review by experienced researchers in your field

- rapid publication on acceptance

- support for research data, including large and complex data types

- gold Open Access which fosters wider collaboration and increased citations

- maximum visibility for your research: over $100 \mathrm{M}$ website views per year

At $\mathrm{BMC}$, research is always in progress.

Learn more biomedcentral.com/submissions 